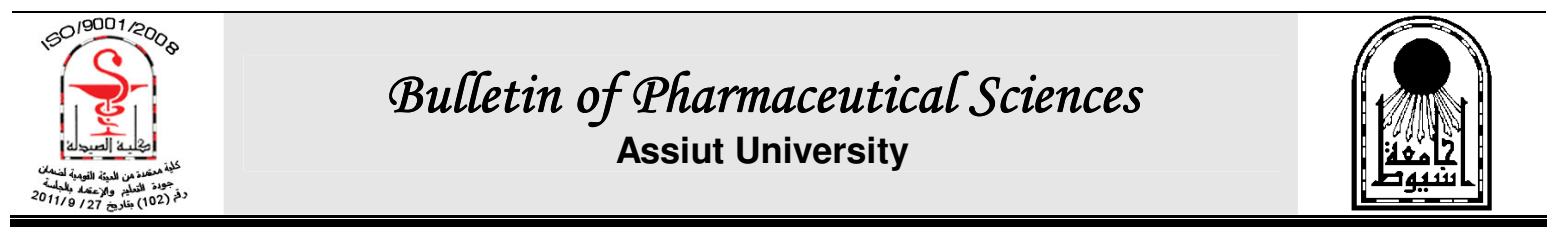

\title{
IN-VITRO AND IN-VIVO EVALUATION OF SUSTAINED-RELEASE SUPPOSITORIES CONTAINING THEOPHYLLINE MICROSPHERES
}

\author{
Gamal M. Mahrous ${ }^{1}$, Gamal A. Shazly ${ }^{1,2}$, Sayed H. Auda ${ }^{1,3}$ and Hesham M. Tawfeek ${ }^{2}$ \\ ${ }^{1}$ Department of Pharmaceutics, King Saud University, PO Box 2457, Riyadh 11451, Saudi \\ Arabia \\ ${ }^{2}$ Department of Industrial Pharmacy, Faculty of Pharmacy, Assiut University 71526, Assiut, \\ Egypt \\ ${ }^{3}$ Department of Pharmaceutics and Industrial Pharmacy, Faculty of Pharmacy,Al-zhar \\ University, Assiut, Egypt
}

\begin{abstract}
The sustained release microspheres of theophylline were formulated using non-solvent addition technique. The in-vitro dissolution of the drug from the fabricated microspheres that having size ranges of 300-600, 600-800 and 800-1000 $\mu \mathrm{m}$ was tested. The release of theophylline was extended over 8 hrs and it was found that the drug release decreased nonsignificantly as the particle size increased ( $p \geq 0.05$ ). Incorporating theophylline-containing microspheres into suppository formulation using polyethylene glycol base resulted in a slight increase in dissolution rate, but still in a sustained release pattern over 8 hrs. In-vivo study of the prepared suppositories on beagle dogs revealed that the peak of theophylline serum concentration $C_{\max }$ (mean $\left.\pm S . D\right)$ was $11.1+0.3 \mu \mathrm{g} / \mathrm{mL}$. It was also found that $A U C_{(0-24 h r s)}$ value averaged $154.7 \pm 20.3 \mu \mathrm{g}-\mathrm{h} / \mathrm{ml}$. The median peak time $\left(T_{\max }\right)$ was $3.0 \mathrm{hrs}$ and MRT was $13 \mathrm{hrs}$ indicating a sustained effect.
\end{abstract}

\section{INTRODUCTION}

Sustained release dosage forms are of increasing importance in drug therapy. These dosage forms are developed to give a slower rate of drug release which maintains drug levels at uniform therapeutic for an extended period. Sustained release dosage forms had many advantages such as reduction of the dose intervals, less adverse effects and improved the patient compliance ${ }^{1}$. The effective formulation that control drug release for the wanted duration and required release profile depends on many factors. Among these are the physical and chemical characteristics of the drug, the type of the polymer, ratio of polymer to drug, and the type of the plasticizer $^{2-8}$. From last decade, much attention was focused on polymeric microcapsules and microspheres as drug delivery systems to modify and extend the drug release ${ }^{9}$. The formulation depends on the use of inert polymeric materials to coat the drug particles that allows the drug diffusion at a predictable and controlled rate in the release vehicle $^{10}$. Several methods were applied to make polymeric microspheres as sustained release delivery systems for many drugs. Examples of these methods include: mechanical treatments (such as spray drying), physicochemical processes (solvent evaporation technique or phase separation method) and the non-solvent addition method ${ }^{11-17}$.

Theophylline is one of the wellestablished drugs that used in the treatment of asthma. It has a narrow therapeutic index; with plasma concentrations of $5-20 \mu \mathrm{g} / \mathrm{mL}^{18}$. Extended release formulations of theophylline that can maintain more uniform serum drug concentrations with less fluctuation in peakthrough levels could be useful. The objective of this work was to formulate extended release 
microspheres of the investigated drug theophylline, using ethylcellulose as a polymer for release-retardation, using the non-solvent addition method. Then the prepared microspheres were incorporated into suppositories dosage form followed by studying the in-vitro release and in-vivo absorption from the prepared suppositories.

\section{MATERIALS AND METHODS}

\section{Materials}

Theophylline (Theo) was purchased from Sigma Chemicals (St. Louis, MO, USA). Ethylcellulose (EC), with viscosity of approximate $14 \mathrm{cp}$ for $5 \%$ solution in 80:20 toluene: ethanol by weight and 2.42 to 2.53 degree of substitution was supplied from Fluka Chemie AG (Switzerland). Petroleum ether, polyehelyne glycol 1540 and 4000 (PEG) and toluene were obtained from BDH Chemicals Ltd. (Poole, England). Diethylphthalate was purchased from Riedel-DE Haenag(Germany).

\section{Methods \\ Preparation of theophylline loaded microspheres}

Theophylline loaded Microspheres were prepared using the previously reported nonsolvent addition method ${ }^{19}$. Microspheres composed of 1:1 w/w EC: Theo ratio was prepared. The pre calculated and weighted quantity of theophylline $(2.5 \mathrm{~g})$ was dispersed in fifty $\mathrm{ml}$ of toluene in which ethyl cellulose polymer $(2.5 \mathrm{~g})$ was previously dissolved, and the mixture subjected to stirring at $700 \mathrm{rpm}$ for 15-minutes using paddle stirrer. Model Lightnin L. T52010, USA. Diethylphthalate (as plasticizer) was added to the EC polymeric solution in a concentration of $10 \%$ of EC content and stirred for additional 15 minutes. Then, one hundred $\mathrm{ml}$ petroleum ether was added drop wise to the mixture with continuous stirring for $2 \mathrm{hrs}$ at room temperature $\left(25^{\circ} \mathrm{C}\right)$. After decantation, the produced microspheres were thoroughly washed with fifty $\mathrm{ml}$ petroleum ether in three portions, to remove the excess toluene from the microspheres. The obtained microspheres were filtered off and then allowed to dry in the open air until complete drying. The dried microspheres were subjected to sieve analysis using set of sieves and three fractions $(0.3$ to $<0.6,0.6$ to $<0.8$ and 0.8 to $<1 \mathrm{~mm}$ ) were used for further studies.

Determination of drug content of the prepared microspheres

A weighed quantity of microspheres equivalent to $100 \mathrm{mg}$ theophylline was transferred to a volumetric flask, $50 \mathrm{ml}$ ethanol was added and the flask sonicated in a sonicator water path for 30 minutes to attain complete extraction of the drug. After Millipore filtration, theophylline concentration was spectrophotometrically assayed at $\lambda_{\max }$ of 272nm using spectrophotometer Philips $\mathrm{Pu}$ 8620, England, UK. Each experiment was carried out in triplicate. Theophylline content was calculated as a percentage of the drug theoretical content in the microspheres. Plain microspheres without drug, prepared and extracted in the same way, were used as reference blank.

\section{Preparation of suppositories containing theophylline microspheres}

Suppository bases were prepared using the composition of PEG 1540 and PEG 4000, in a ratio of $1: 3 \mathrm{w} / \mathrm{w}$, by the fusion method. Theophylline microspheres $(0.3$ to $<0.6 \mathrm{~mm}$ size) equivalent to $100 \mathrm{mg}$ theophylline were added to the fused bases and dispersed by continues stirring for $10 \mathrm{~min}$. The mixture was then transferred to suppository molds (capacity $2 \mathrm{~g}$ ), that were immediately put in a refrigerator.

\section{In-vitro release studies}

Dissolution experiments were done using USP dissolution instrument 2 , at $50 \mathrm{rpm}$ (Caleva Ltd., Model 85T) connected to an automated monitoring system that composed of an IBM computer PK 8620 series and PU $8605 / 60$ dissolution test software, Philips VIS/UV/NIR single beam eight cells spectrophotometer Model PU 8620, Epson FX 850 printer, and Watson-Marlow peristaltic pump. In each vessel, 0.9 liter phosphate buffer $\mathrm{pH} 7.4$ was used as a dissolution medium. The temperature was kept at $37 \pm 0.5^{\circ} \mathrm{C}$. A defined weight of the formulated microspheres equivalent to $100 \mathrm{mg}$ of theophylline, or one suppository was put to each vessel. All the release experiment was done in triplicate and the absorbance was recorded automatically at 
$\lambda_{\max }$ of $272 \mathrm{~nm}$ up to $8 \mathrm{hrs}$. The amount of drug released was computed as a function of time.

\section{In-vivo study}

According to the approved protocol by the Institutional Review Board-Use and care of Animals at King Saud University for the invivo study, six male of beagle dogs $(8-14 \mathrm{~kg})$ were used for this study. The dogs were housed in separated cages at $25 \pm 1^{\circ} \mathrm{C}$ and $45-55 \%$ relative humidity with a $12 \mathrm{hrs}$ light/dark cycle. All dogs were fasted overnight before the investigation. Water was available throughout the study period. The tested formulation was administered rectally to each dog. The dog's leg was shaved and blood samples were collected from a forefoot vein using cannula of an 18 gauge size. Serial $3 \mathrm{ml}$ blood samples were taken from the tested animals just before the administration of the tested doses and at time intervals $(0.5,1,1.5,2,3,4,6,8,10,12$, and $24 \mathrm{hrs}$ ) after rectal administration. Heparinized blood samples were centrifuged immediately for $15 \mathrm{~min}$ at $3500 \mathrm{rpm}$, and the plasma was collected in glass vials and kept frozen at $-20^{\circ} \mathrm{C}$ until further analysis. The amount of theophylline in the plasma was investigated by the high-performance liquid chromatography method of Al Janobi et al. ${ }^{20}$ as detailed below:

\section{1- Theophylline plasma assay}

An integrated high-performance liquid chromatography system (LC 2010C; Shimadzu Corporation, Kyoto, Japan) equipped with a column oven, a degasser, a UV detector, a quaternary pump (LC20AD), an auto-sampler (CIL20A) and a data analysis software was used to determine plasma theophylline concentrations. A C18 column $(5 \mathrm{~mm}, 150 \mathrm{~mm}$ $4.6 \mathrm{~mm}$, Waters Corporation, Milford, MA) at $25^{\circ} \mathrm{C}$ was used for separation of theophylline. A mixture of HPLC water/ acetonitrile (93:7, $\mathrm{v} / \mathrm{v})$ with a $\mathrm{pH}$ of 4.2 adjusted with glacial acetic acid $(0.5 \mathrm{~mL} / \mathrm{L})$ was used as a mobile phase that pumped at a flow rate of $1.0 \mathrm{~mL} /$ min. The wavelength of detection was set at $\lambda_{\max }$ of $272 \mathrm{~nm}$.

\section{2- Sample preparation}

Samples were prepared by pipetting plasma samples $(0.2 \mathrm{~mL}$ each) into microcentrifuge tubes. After that, $0.1 \mathrm{~mL}$ of hydroxyethyl theophylline as internal standard (I.S.) working solution $(250 \mu \mathrm{g} / \mathrm{mL})$ was added and the blend was mixed by vortex for $30 \mathrm{~s}$. Then, $0.7 \mathrm{~mL}$ of zinc sulfate solution (2\%) was added for protein precipitation followed by vortex mixing for $1 \mathrm{~min}$. The samples were then centrifuged at $3000 \mathrm{~g}$ for $15 \mathrm{~min}$ at $25^{\circ} \mathrm{C}$. The clear supernatant was transferred into injector vials and a $50 \mu \mathrm{L}$ aliquot was injected into the HPLC system. Standard stock solutions of theophylline $(1 \mathrm{mg} / \mathrm{mL})$ and I.S. $(1 \mathrm{mg} / \mathrm{mL})$ were made for calibration and control samples using methanol as a solvent. The internal standard (I.S) working solution $(250 \mu \mathrm{g} / \mathrm{mL})$ was prepared by diluting the stock solution with the mobile phase. The working solutions of theophylline and I.S. $(0.2 \mathrm{~mL})$ were added to drug-free plasma $(9.6 \mathrm{~mL})$ to obtain final concentrations of $0.1,0.25,0.5,1.0,2.5,5.0$, 10.0 and $25.0 \mu \mathrm{g} / \mathrm{mL}$.

\section{Statistical analysis}

Software Graph Pad Prism5 (Graph Pad Software, La Jolla, USA) was used to analys the results by applying one-way ANOVA. The difference between formulations was considered to be significant if $\mathrm{p} \leq 0.05$.

\section{RESULTS AND DISCUSSION}

One of the essential polymeric materials used in microspheres and microencapsulation preparations is the ethyl cellulose polymer ${ }^{21-23}$. This is because ethyl cellulose has advantages of its cheapness, good stability, high safety and easy of fabrication ${ }^{16}$. Different sizes (ranging from $\leq 300-1250 \mu \mathrm{m}$ ) of theophylline microspheres were successfully prepared. The results of drug content of the prepared microspheres showed that theophylline content was ranged from 95 to $102 \%$ of the theoretical content, representing high encapsulation efficiency. It was found that the total yield was not less than $70 \%$ in all formulations.

\section{In-vitro release from the prepared microspheres}

Figure 1 demonstrates the cumulative percent released of theophylline from the microspheres batches (particle sizes 0.3 to $<$ $0.6,0.6$ to $<0.8$ and 0.8 to $<1 \mathrm{~mm}$ ). The results presented that the release of theophylline from the microspheres of different batches was 
prolonged over $8 \mathrm{hrs}$. It was evident from the release pattern that there was no significant difference $(P>0.05)$ between the batches of microsphere particle sizes of 0.3 to $<0.6 \mathrm{~mm}$ and those of size ranges 0.6 to $<0.8 \mathrm{~mm}$. These results are similar with the previously published data by Ibrahim et al. ${ }^{19}$ the release data of theophylline from the prepared microspheres were subjected to various kinetic models (zero order, first order and Higuchi diffusion models). The results are presented in Table 1. The results obtained showed that the drug release from the prepared microspheres followed Higuchi model as it showed the highest correlation coefficient.

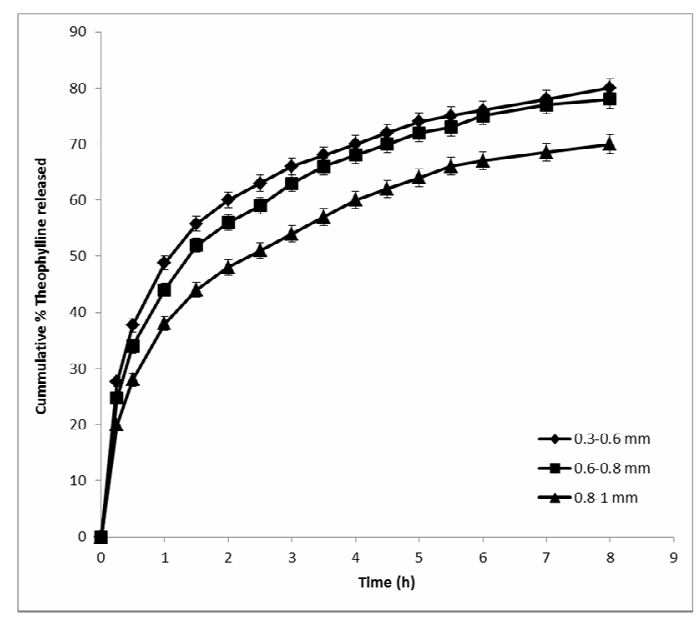

Fig. 1: Effect of particle size on the in-vitro release of theophylline from the prepared microspheres.
In-vitro release of theophylline from the suppositories containing theophylline microspheres

The release pattern of theophylline from suppositories containing microspheres is displayed in figure 2 . These results reveal that the release rate of theophylline from suppositories was initially comparable in the first hour to the microsphere, and then slightly increased in the following time intervals. The release reached $92 \%$ after 8 hrs. The slight increase in the drug release from theophylline microspheres incorporated in suppositories may be due to the enhancement effect of PEG.

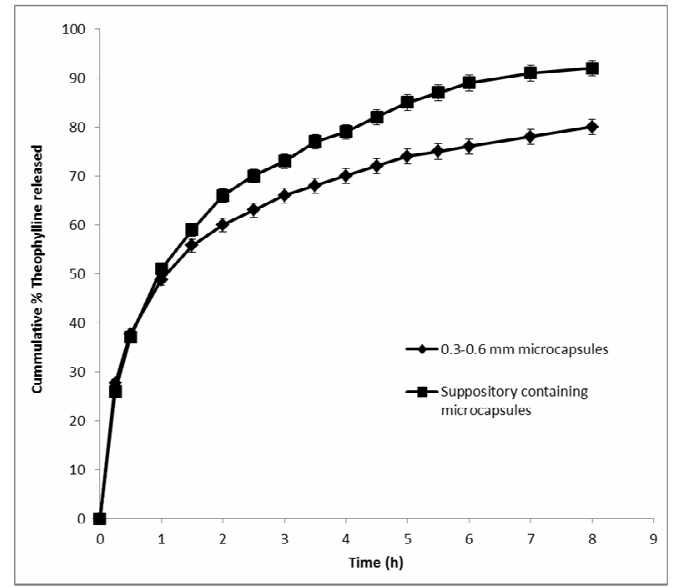

Fig. 2: In-vitro release of theophylline from the prepared microspheres and the microspheres containing-suppositories.

Table 1: Comparison of correlation coefficient (r) obtained from in-vitro release data of theophylline microspheres.

\begin{tabular}{|l|c|c|c||}
\hline \multicolumn{1}{|c|}{ Release order } & \multicolumn{3}{c|}{ r value for different sizes of microspheres } \\
\hline & 0.3 to $<0.6 \mathrm{~mm}$ & 0.6 to $<0.8 \mathrm{~mm}$ & 0.8 to $<1 \mathrm{~mm}$ \\
\hline Zero Order & 0.841 & 0.858 & 0.864 \\
\hline First Order & 0.940 & 0.936 & 0.941 \\
\hline Higuchi diffusion model & 0.961 & 0.966 & 0.969 \\
\hline
\end{tabular}




\section{In-vivo study}

The therapeutic serum concentration of theophylline is optimum when it is ranged from $10-20 \mathrm{mg} / \mathrm{mL}^{24 \& 25}$ however it should not be considered as a rigid barrier; clinical decisions should never depend solely on the serum concentrations $^{26}$. Several articles were available dealing with food effects on the pharmacokinetics of theophylline ${ }^{27-30}$. However, the present study, theophylline was rectally administered and the pharmacokinetic of its formulations was studied, so food effects are not essential. Figure 3 shows the mean theophylline plasma concentrations from the tested suppositories in beagle dogs after rectal administration. The results showed that the serum concentration peak of theophylline $\mathrm{C}_{\max }$ (mean \pm S.D) was $11.1 \pm 0.3 \mu \mathrm{g} / \mathrm{mL}$ for the tested theophylline suppository as shown in table 2 . It was also found that $\mathrm{AUC}_{(0-24 \mathrm{hrs})}$ value averaged $154.7 \pm 20.3 \mu \mathrm{g}-\mathrm{h} / \mathrm{ml}$ and the median peak time $\mathrm{T}_{\max }$ was $3.0 \mathrm{hrs}$. for theophylline suppositories (Table 2). In a previous study ${ }^{31}$, after administration of $200 \mathrm{mg}$ theophylline orally to beagle dogs, the maximum plasma theophylline concentration $\mathrm{C}_{\max }$ (mean \pm S.D) was $16.4 \pm 0.7$ $\mu \mathrm{g} / \mathrm{mL}$ and the median peak time $\mathrm{T}_{\max }$ was 2.1 hrs. Also, as previously reported, the median peak time $T_{\max }$ for pediatric regular theophylline PR (Minophylline suppositories), is within 30 minutes as a reported value for pediatric theophylline PR. ${ }^{32}$. Another published data $^{33}$ revealed that the theophylline pharmacokinetics was evaluated in 24 healthy males after rectal administration of theophylline ethanoate (Minophylline $500 \mathrm{mg}$ ). The median peak time, $\mathrm{T}_{\max }$ was $0.5 \mathrm{hr}$ for theophylline rectal administration. However, in this study, the median peak time $\mathrm{T}_{\max }$ was $3.0 \mathrm{hrs}$ indicating a sustained effect.

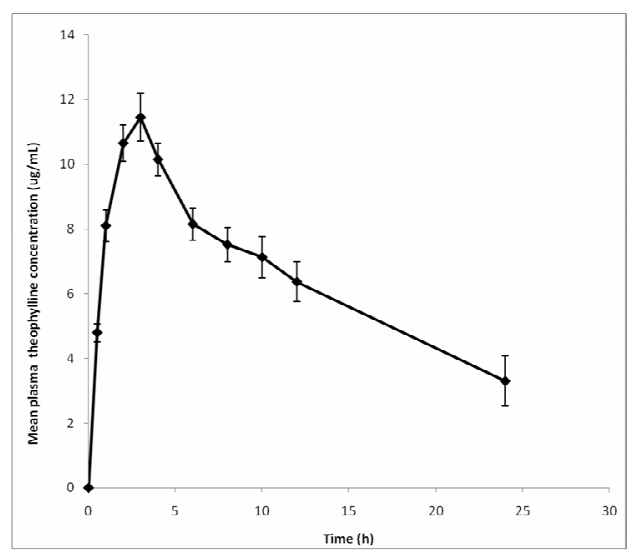

Fig. 3: Mean theophylline plasma concentration time curve after rectal administration of suppository contains microspheres equivalent to $100 \mathrm{mg}$ theophylline $(n=6)$.
Table 2: Pharmacokinetic parameters of sustained release theophylline suppositories $(100 \mathrm{mg})$ after rectal administration to beagle dogs $(n=6)$.

\begin{tabular}{|l|l|}
\hline \multicolumn{1}{|c|}{ Parameter } & \multicolumn{1}{c|}{ Value } \\
\hline $\mathrm{C}_{\max }$ & $11.1 \pm 0.30 \mu \mathrm{g} / \mathrm{ml}$ \\
\hline $\mathrm{T}_{\max }$ & $3.0 \pm 0.2 \mathrm{hrs}$ \\
\hline $\mathrm{AUC}_{(0-24)}$ & $154.7 \pm 20.3 \mu \mathrm{g}-\mathrm{h} / \mathrm{ml}$ \\
\hline $\mathrm{AUC}_{(24-\mathrm{end})}$ & $61.7 \pm 8.8 \mu \mathrm{g}-\mathrm{h} / \mathrm{ml}$ \\
\hline $\mathrm{MRT}$ & $13.1 \mathrm{hrs}$ \\
\hline $\mathrm{K}_{\mathrm{ab}}$ & $184.495 \mathrm{hr}^{-1}$ \\
\hline $\mathrm{K}_{\mathrm{el}}$ & $0.053446 \mathrm{hr}^{-1}$ \\
\hline
\end{tabular}

\section{Conclusion}

From the present data, it was found that a good dissolution rate from theophylline microspheres was attained by preparing theophylline microspheres with a ratio of $1: 1$ ethyl cellulose: theophylline, of particle size ranging from 0.3 to $<1 \mathrm{~mm}$, and containing $10 \%$ diethylphthalate as a plasticizer. The results showed that the release rate of theophylline from the prepared suppositories was initially comparable in the first hour to the microsphere, and then slightly increased in the following time intervals. Bioavailability of the prepared suppositories in beagle dogs showed median peak time $\mathrm{T}_{\max }$ of $3.0 \mathrm{hrs}$ and plasma drug concentration above $5 \mu \mathrm{g} / \mathrm{ml}$ for more than $12 \mathrm{hrs}$ indicating a sustained effect.

\section{Acknowledgment}

The authors would like to extend their sincere appreciation to the Deanship of Scientific Research at King Saud University for its funding this Research group No. RGP -299.

\section{Disclosure}

The authors report no conflicts of interest in this work. 


\section{REFERENCES}

1- J. D. Rogers and K. C. Kwan, "Pharmacokinetic Requirements for Controlled-Release Dosage Forms", In: John Urquhart, Ed. Controlled-Release Pharmaceuticals, Academy of Pharmaceutical Sciences, American Pharmaceutical Association, 1979, pp. 95-119.

2- H. Takenaka, Y. Kawashima and S. Y. Liu, "Micromeritic properties of sulfamethoxazole microcapsules prepared by gelatin-acacia coacervation", J. Pharm. Sci., 69, 513-16 (1980).

3- Y. Pongpaibul, K. Maruyama and M. I. watsura, "Formation and in-vitro evaluation of theophylline-loaded poly (methylmethacrylate) microspheres", $\boldsymbol{J}$. Pharm. Pharmacol., 40, 530-33 (1988).

4- M. G. Moldenhaver and J. G. Nairn, "Formulation parameters affecting the preparation and properties of microencapsulated ion-exchange resins containing theophylline", J. Pharm. Sci., 79, 659-66 (1990).

5- S. H. Khidr, E. M. Niazy and Y. M. ElSayed, "Preparation and in-vitro evaluation of sustained-release metoclopramide hydrochloride microspheres", $\boldsymbol{J}$. Microencapsulation, 12, 651-60 (1995).

6- M. A. Bayomi, S. A. Al-Suwayeh, A. M. El-Helw and A. F. Mesnad, "Preparation of casein-chitosan microspheres containing diltiazem hydrochloride by an aqueous coacervation technique", Pharm. Acta. Helv., 73, 187-92 (1998).

7- A. M. El-Helw and M. A. Bayomi, "Effect of core modification on the release of chlorpheniramine maleate from ethylcellulose and cellulose acetate propionate microspheres", Saudi Pharmaceutical Journal, 8, 31-8 (2000).

8- Y. Miyazaki, S. Yakou, T. Nagai and K. Takayama, "Release profiles of theophylline from microspheres consisting of dextran derivatives and cellulose acetate butyrate: Effect of polyion complex formation", Drug Dev. Ind. Pharm., 29 (7), 795-804 (2003).

9- C. Berkland, K. Kim, and D. W. Pack, "PLG microsphere size controls drug release rate through several competing factors", Pharm. Res., 20, 1055-1062 (2003).

10- E. A. Hosny, A. M. El-HelwA and E. M. Niazy, "In-vitro and in-vivo evaluation of commercial and microencapsulated sustained release tablets containing diclofenac Sodium", Saudi Pharmaceutical Journal, 6, 65-70 (1998).

11- K. Suzuki and J. C. Price, "Microencapsulation and dissolution properties of a neuroleptic in a biodegradable poly (d, 1-Lactide)", $\boldsymbol{J}$. Pharm. Sci., 74, 21-4 (1985).

12- O. L. Sprockel and W. A. Prapaitrakul, "Comparison of microencapsulation by various emulsion techniques", Int. J. Pharm., 58, 123-27,(1990).

13- A. A. Bosela, "Bioavailability and in-vitro evaluation of microencapsulated nitrofurantoin", J. Bio. Med. Sci. Ther., 7, 423-38 (1991).

14- B. C. Thanoo, M. C. Sunny and A. Jayakrishnan, "Oral sustained-release drug delivery systems using polycarbonate microspheres capable of floating on the gastric fluid", J. Pharm. Pharmacol., 45, 21-4 (1993).

15- M. A. Bayomi, S. H. Khidr , S. A. AbdElhady and A. A. AlAngary, "Formulation, in-vitro and in-vivo evaluation of sustained release mebeverine hydrochloride microspheres", Die Pharmazeutische Industrie, 56, 192-94 (1994).

16- S. J. Cheu, R. R. L. Chen, P. F. Chen and W. J. Lin, "In-vitro modified release of acyclovir from ethyl cellulose microspheres", J. Microencap., 18, 55965 (2001).

17- M. Rafienia, F. Orang and S. H. Emami, "Preparation and characterization of polyurethane microspheres containing theophylline", J. Bioact. Compat. Polym., 21, 341-349 (2006).

18- M. A. Bayomi, S. A. Al-Suwayeh and A. M. El-Helw, "Excipient-excipient interaction in the design of sustained release theophylline tablets: In-vitro and In-vivo evaluation", Drug Dev. Ind. Pharm., 27, 489-96 (2001).

19- I. M. El-Bagory, E. A. Hosny, S. A. AlSuwayeh, G. M. Mahrous and F. I. AlJenoobi, "Effects of sphere size, polymer 
to drug ratio and plasticizer concentration on the release of theophylline from ethylcellulose microspheres", Saudi Pharm. J., 15 (3-4), 213-217 (2007).

20- F. I. Al-Jenoobi, Abdul Ahad, G. M. Mahrous, M. Raish, M. A. Alam and A. M. Al-Mohizea, "A Simple HPLC-UV Method for the Quantification of Theophylline in Rabbit Plasma and its Pharmacokinetic Application", J. Chromatogr. Sci., 1-6 (2015).

21- S. Benita and M. Donbrow, "Release kinetics of sparingly soluble drugs from ethylcellulose-walled microspheres: Theophylline microspheres", J. Pharm. Pharmacol., 34, 77-82 (1982).

22- S. Goto, T. Uchida and T. Aoyama, "Preparation and biopharmaceutical evaluation of microspheres of ampicillin", J. Pharmcobiodyn., 8, 270-77 (1985).

23- S. Y. Lin and J. C. Yang, "Bioavailability studies of the theophylline ethylcellulose microspheres prepared by using ethylenevinyl acetate copolymer as a coacervationinducing agent", J. Pharm. Sci., 76, 19-23 (1987).

24- N. Holford, P. Black, R. Couch, J. Kennedy and R. Briant, "Theophylline target concentration in severe airways obstruction-10 or $20 \mathrm{mg} / \mathrm{L}$. A randomized concentration-controlled trial", Clin. Pharmacokinet., 25, 495-505 (1993).

25- L. Hendeles, J. Jenkins and R. Temple, "Revised FDA labeling guideline for theophylline oral dosage forms", Pharmacother., 15, 409-427 (1995).

26- J. P. Hampson, "The theophylline, therapeutic window, fact or fallacy", Pharm. J., 241, 722-774 (1988).
27- J. H. Jonkman, "Food interactions with sustained-release theophylline preparations: A review", Clin. Pharmacokinet., 16, 162-179 (1989).

28- D. Juan, S. G. Shin, M. Fisher and R. L. Hughes, "Impairment of theophylline clearance by a hypocaloric low-protein diet in chronic obstructive pulmonary disease", Therapeut. Drug Monit., 12, 111-114 (1990).

29- J. Kann, M. J. Levitt, J. W. Horodniak and J. W. Pav, "Food effects on the night time pharmacokinetics of Theo-Dur tablets", Ann. Allergy, 63, 282-286 (1989).

30- N. H. Leeds, P. Gal, A. A. Purohit and J. B. Walter, "Effect of food on the bioavailability and pattern of release of sustained-release theophylline tablets", $\boldsymbol{J}$. Clin. Pharmacol., 22, 196-200 (1982).

31- Martindale, "The Extra Pharmacopoeia", $31^{\text {st }}$ Ed. Reynolds, J. E. F., Ed. Royal Pharmaceutical Society: London, 1996, p. 1657.

32- F. I. Al-Jenoobi, Abdul Ahad, G. M. Mahrous, A. M. Al-Mohizea, M. K. AlKharfy and S. A. Al-Suwayeh, "Effects of fenugreek, garden cress, and black seed on theophylline pharmacokinetics in beagle dogs", Pharm. Biol., 53 (2), 296 (2015).

33- L. I. Abou-Basha, L. F. Wahman, A. Hamza and Y. Hassan Aboul-Enein, "Pharmacokinetics of Theophylline after Administration of Suppositories Formulation", J. Immunoassay Immunochem., 26 (4), 251-258 (2005). 


نشرة العلوم الصيدليــة

التقييم الحيوي والمعملى للبوسات ممتدة المفعول محتوية على كريات دقيقة من الثيوفيلين

جمال محمد محروس' - جمال عبد الغنى شاذلى'، " سيد حسن عودة'،r - هشام محمد توفيق'

'قسم الصيدلانيات ، جامعة الملك سعود ، الرياض ، المملكة العربية السعودية

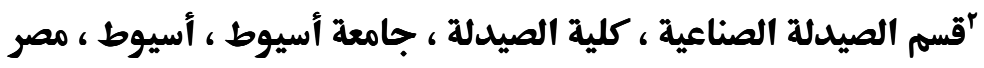

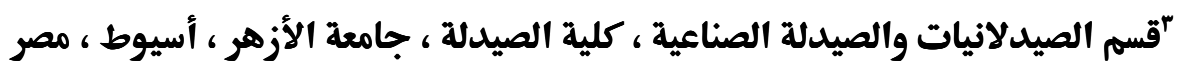

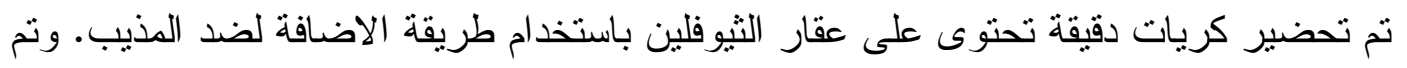

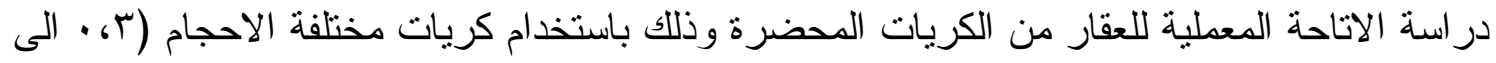

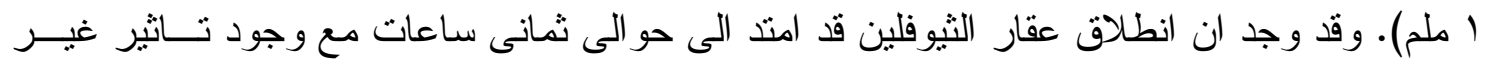

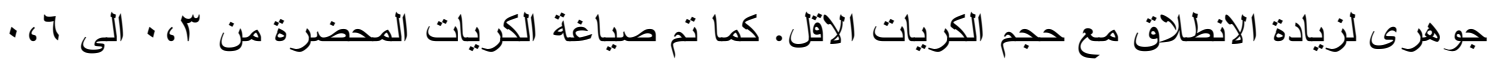

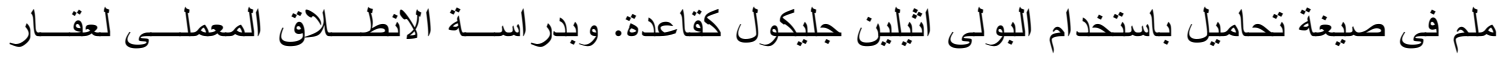

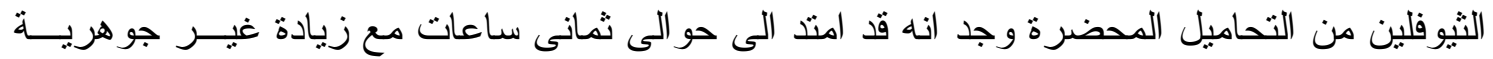

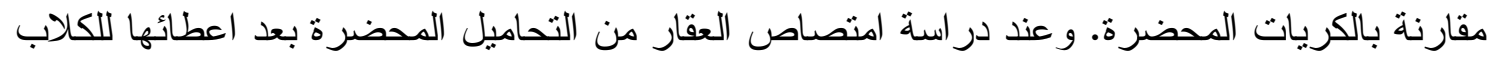

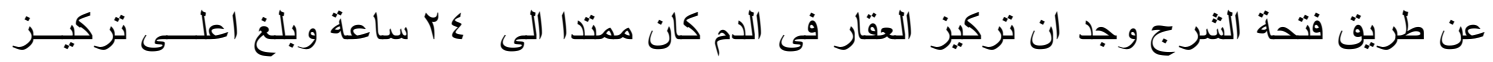
لعقار الثيوفلين فى البلازما عند ب ساعات. 